\title{
Research on the Improvement of Practical Teaching Ability in College
}

\author{
Xu Zhengru ${ }^{1, \mathrm{a}}$, Meng Yanmei ${ }^{1, \mathrm{~b}}$ \\ ${ }^{1}$ Qingdao Huanghai University \\ Qingdao, China \\ a290357329@qq.com, b1142169699@qq.com
}

\begin{abstract}
Practical teaching is an effective way to consolidate the theoretical knowledge and deepen the understanding of the theory. It is an important link for cultivating high quality engineering technicians with innovative consciousness, and an important platform to link theory with practice, to train students to master scientific methods and to improve their ability. The development and optimization of practical teaching are studied in the paper. It can be known that the construction of practical teaching system should fully reflect the requirements of professional positions and closely relate to the development of professional post groups. Based on this principle, a practical teaching system with clear levels and clear division of labor is formed. This system is conducive to the improvement of students' literacy and their formation of correct values. College teachers should have a clear division of labor and corresponding post responsibilities in practice teaching. The practical teaching staff should actively undertake the practice teaching work according to the management standard of each practice teaching link, and strive to complete all practical teaching tasks.
\end{abstract}

Keywords-Practical teaching; College teaching; Innovation teaching; Reform

\section{INTRODUCTION}

It is one of the important tasks of higher education to cultivate high-quality and practical talents that meet the requirements of employers and have the ability of innovation and practical work. And many excellent university teachers with strong practical teaching ability are the fundamental guarantee for achieving the above educational goals. Teachers' practical teaching ability is the ability of teachers to integrate professional knowledge and operational skills on the basis of mastering the relevant practical operation skills of the major, and to cultivate the students' comprehensive professional ability teaching process. At present, the intrinsic motivation of teachers to improve their practical teaching ability is generally insufficient. This is mainly reflected in the fact that they are accustomed to imparting knowledge in class instead of doing practical operations in enterprises [1]. The educational administration department does not take the practical teaching ability as the basic condition for the promotion of the teacher's title, and the scientific research results and the number of published papers are the basic requirements to measure the teacher's promotion. The insufficiency of teachers' practical teaching ability directly affects the training of the comprehensive abilities of applied talents, and affects the development of various specialties and disciplines in schools. It can be said that the cultivation and upgrading of practical teaching ability is imminent [2]. On the basis of improving the level of teachers' theoretical knowledge and strengthening the improvement of teachers' practical teaching ability, it is an important way to improve the quality of training innovative and practical talents. Therefore, improving teachers' practical teaching ability is not only an important condition for improving the quality of personnel training in Colleges and universities, but also an inevitable requirement for the connotative development of universities. From the following aspects, this paper explores the effective strategies to improve the teaching ability of teachers with the help of the team platform, in order to adapt to the development of the education and teaching of the times and improve the quality of talent cultivation in an all-round way [3].

\section{OPTIMIZING THE LAYOUT OF THE SUBJECT}

To effectively improve teachers' practical teaching ability, the college need to be people-oriented so as to stimulate teachers' initiative and enthusiasm to improve their practical teaching ability. Teachers themselves must have the driving force to improve their practical teaching ability, so that they can consciously participate in and actively seek opportunities to improve with the help of policies provided by schools. Teachers should take an active part in social practice and improve their practical teaching ability through various channels and ways. At the same time, teachers should combine their own teaching, scientific research, students and the surrounding work environment, diligently in their own teaching and scientific research practice, and carry on the habit of reflection, in the teaching and scientific research practice to improve the comprehensive ability and teaching practice quality [4]. No teacher has any old books to eat. Only by constantly improving the ability of practical teaching can he keep pace with the times. 


\section{A. Improving the talent training mode}

Based on the needs of the society, the college should set up corresponding training system and distinctive training programs for different teachers. The compulsory course system of interdisciplinary, cross professional and cross school needs to be constructed. The reform of the credit system needs to be fully implemented. The proportion of elective and practical courses needs to be expanded, and the diversity and individualization of teaching need to be promoted. In addition, we need to further improve the cooperative education mechanism, encourage enterprises and schools to jointly formulate training standards for talents, revise professional courses, implement joint training and order training, introduce enterprise production and management standards and environment into the teaching process, and establish an integrated training model of teaching process and enterprise production process.

\section{B. Optimizing the structure of subject specialty}

The college teachers need to focus on regional economic development and industrial transformation and upgrading, constantly optimize the structure of disciplines and specialties, and add new engineering related specialties or projects. At the same time, the teaching method should deepen the integration of production and education, deepen the innovation of innovation and entrepreneurship education, optimize the training program and mode of talent training, and improve the environment and platform of engineering practice. We should update teaching contents dynamically, promote the continuous improvement of professional connotation construction level, and strive to get widespread attention and recognition from all walks of life. Colleges and universities should build a four - in - one practical education system, which are composed of practical education target system, practical education content system, practical education management system and practical education guarantee system, and strengthen the training of teachers' practical ability and innovation ability.

\section{COLLABORATIVE INNOVATION}

University teachers need to continue to give play to the role of collaborative innovation centers in service areas and industrial development. In the time teaching, teachers take the position of enterprise innovation as the main body to promote the close integration of technology and economy. Schools should help teachers create conditions to help large and mature technology innovation enterprises to be strong and excellent, and set up a benchmark for leading enterprises in the city to innovate and develop.

\section{A. Strengthening the transfer and transformation of scientific research results}

Teachers' practical teaching needs to actively promote the transformation and transfer of scientific and technological achievements, improve the quality of $\mathrm{R} \& \mathrm{D}$ output, and further play the role of the main body of enterprises. It is certain that speeding up the construction of the transformation mechanism of scientific and technological achievements, and actively promoting the implementation of the national "action plan for promoting the transformation of scientific and technological achievements" is necessary, which can solve the problem of high speed and effective transformation of scientific and technological achievements to practical productive forces [5]. The school needs to adjust and optimize the professional layout to form a number of professional groups based on core specialties and many similar specialties. Based on the construction of professional groups, two levels of college or department are adjusted and formed.

\section{B. Creating and promoting the development of the teachers' practice platform}

Teachers in Colleges and universities should focus on the construction of new and high technology development zones and give full play to the important platforms of various development zones. At the same time, the emerging industries should be taken as the dominant innovation unit, with the major scientific and technological tasks tackling key issues and the large scale science and technology infrastructure as the main line, which can provide continuous scientific and technological strength for the enterprises in the region. Finally, teachers need to make full use of the technology incubator platform, implement the market oriented strategy, play an important role in cultivating small and medium science and technology enterprises and high-tech industries, and improving the regional innovation system.

\section{INTRODUCING HIGH LEVEL TALENTS}

\section{A. Building an innovation system}

Through continuously strengthening the construction of engineering laboratories, the Institute has carried out basic research, pre competition high technology research and social public welfare research, breaking through the industrial structure adjustment and key technical equipment constraints in the development of key industries, strengthening the technical support and guarantee of major strategic tasks and key projects of the state and provinces and cities, and increasing production. The independent innovation ability and core competitiveness of the industry.

Colleges and universities should make good use of existing talents and introduce foreign talents. Setting up the talent position is the first position concept. The innovative cause calls for innovative talents, and we should set up the sense of talents in the whole society. Colleges and universities should create a favorable environment for talents growth and attract multi-level talents such as management talents, professional talents and technical talents to create and start businesses. 


\section{B. Strict requirements for teachers in Colleges}

At present, improving the service level and ability of enterprises needs a large number of skills teachers with a comprehensive knowledge of a certain field, which needs high skilled intellectuals with ability to solve problems, selflearning ability and creative thinking ability. From the view of professional ability construction workers, colleges and universities need to solve the problems of lack of high skilled personnel, poor structure and the need for the transformation of new and old kinetic energy. Schools can vigorously support and train outstanding young talents under the age of 40 , and reserve a team of innovative talents with strong scientific research ability and professional knowledge.

\section{Training teachers' adaptability}

The existing people can adapt to the transformation of new and old kinetic energy, and need special training of human resources and social security departments. According to the actual situation, the annual training plans and tasks are rationally determined, and the social forces are encouraged to participate in the training of entrepreneurship, and the enterprise training system has been set up gradually for the diversification of the main body of training, the diversification of training mode, the multi-level training content and the effective coverage of the whole process of entrepreneurship. This training takes the transformation of new and old kinetic energy as a guide to inject new ideas, new ideas and new knowledge into existing talents. In the information age, knowledge talent is not the cost of an enterprise, but the capital of an enterprise. Knowledge talents are the driving force for the continuous development of the economy, and its value is more and more important for the development of enterprises.

\section{Making a good training mechanism for talents}

At present, the role of talent in our hospital is not full, the key is that the system mechanism of talent management is not alive, the decisive role of the market in the allocation of talent resources has not been fully played. Facing the historical opportunity of the transformation of new and old kinetic energy, we should analyze the important talent documents that have already been issued, find out the shortest board of the talent policy, and formulate the policy of the new and old kinetic energy conversion in our hospital.

\section{PROMOTING THE IMPLEMENTATION OF PRACTICAL TEACHING}

\section{A. Design of special research report}

At present, our school has designed and printed 200 questionnaires about the service between enterprises and university teachers. The results show that more than $80 \%$ of the university teachers have the intention to dock with the enterprises, and more than $70 \%$ of the technical personnel have the intention to solve the engineering problems with the university teachers. However, the service of university teachers to enterprises is facing a profound change in the aspects of ideology, production mode, system and mechanism, working mode and so on. Improving system planning and collaborative promotion is the basic condition and system environment for building and promoting the transformation of kinetic energy [6].

At the same time, colleges and universities with high level and application need to follow the frontiers and hot issues of the subject, pay attention to the needs of the national and social development, engage in scientific research, and contribute their own wisdom.

\section{B. Improvement of evaluation mechanism}

To realize the effective service of university teachers to enterprises, first of all, we need to provide scientific research results that can be rapidly transformed to major projects. Colleges and universities are a major research city, undertaking many kinds of scientific research projects at all levels. They are the publication of scientific research papers, the award of achievements, and the large number of patent holders. In terms of scientific research evaluation, schools should not only look at quantity, but also quality, quantity and quality. Whether the scientific research results and the patent are useful is to see whether it promotes the progress of science and technology, whether it promotes the upgrading of the industry, and whether it has led to the development of the economy. If we only want to evaluate the number of titles, we will lose the importance of scientific research if we only put the titles of scientific research on the shelf after winning the prize.

\section{Teachers development in school system}

Professional skills, enterprising spirit, communication ability and team consciousness are necessary abilities for teachers to serve enterprises, and are also important directions for teachers' personal development. As a university teacher, we should strive to have expertise and extensive hunting, not only proficient in theoretical subjects, but also research related engineering practice problems. At the same time, we should use theory to direct our work practice and raise our work practice to theory. Teachers' personal development cannot be separated from the support of the school system. In view of the actual situation of teachers, our school has formulated a series of management systems, covering various fields, such as practical teaching, teaching implementation, education and teaching evaluation, communication and cooperation, reflection and development, and other areas related to teachers' professional competence. At present, schools are actively contributing, contributing and encouraging young and middle-aged teachers to go out to train professional skills, study abroad and attend academic conferences.

For the high-end talents, we need to implement the policy of rewarding scientific and technological achievements and awarding scientific research results, and explore the implementation of special management equity system in some emerging economic sectors. The implementation of the autonomy of universities and research institutes and the reform of the management system of performance salary in Colleges and universities are conducive to mobilizing the enthusiasm of researchers in innovation. In the new era and new situation, University researchers should aim at the frontier of international science and technology, actively serve the 
major strategy of the country, and actively meet the major needs of the regional economic and social development.

\section{CONCLUSION}

Engineering changes the world, and science and technology create the future. Our college will take the new and old kinetic energy as an opportunity to promote the practical teaching of teachers in our school with new ideas, new requirements and new ways, and promote the construction of our university to a higher level of applied universities. China's economy is still in the process of industrialization. Economic development is inseparable from traditional industries and traditional kinetic energy. On the one hand, we should change old ideas and abandon old ones. On the other hand, we should transform and upgrade traditional kinetic energy and cultivate new development kinetic energy.

\section{REFERENCES}

[1] Lou S Q. "On the Infiltration of Aesthetic Education in College English Teaching". Journal of Nanyang Normal University, 2008, pp.81-86.

[2] Kou S W. "On Across-culture Education in College English Teaching". Journal of Qiqihar University, 2006, pp.311-313.

[3] Kang Z Y. "The Goal of College English Education Theory and Puts Forward Some Countermeasures". Career Horizon, 2012, pp.233.

[4] Zong Y. "On Combining Moral Education with College English Teaching". Journal of Dongguan Institute of Technology, 2003, pp.101104.

[5] Tian-Jun F U, Tao S, Wang X Q. "Steering and Breakthrough of College English Education in Information Age". Journal of Shijiazhuang University of Economics, 2016, pp.99-105.

[6] Cai J. "Characteristics and solutions of college English teaching in transition". Foreign Language Teaching \& Research, 2007, pp.27-32. 